13

\title{
Туннельная эмиссия электронов из наноструктурированных кремниевых катодных матриц с фтор-углеродным покрытием
}

\author{
(C) P.K. Яфраров \\ Саратовский фрилиал Института радиотехники и электроники им. В.А. Котельникова РАН, \\ 410019 Саратов, Россия \\ e-mail: pirpc@yandex.ru
}

Поступило в Редакцию 14 июля 2018 г.

В окончательной редакции 1 ноября 2018 г.

Принято к публикации 1 ноября 2018 г.

Исследованы закономерности изменений морфологических и автоэмиссионных характеристик поверхностно структурированных кремниевых пластин различных типов проводимости, полученных с использованием травления во фторуглеродной плазме и осаждения субнаноразмерных островковых углеродных масочных покрытий. Показано, что поверхностное структурирование с применением фторуглеродной плазмы позволяет получать заданные токи автоэмиссии при различных напряженностях внешних электрических полей. Рассмотрены физико-химические модели механизмов автоэмиссии и разрушения поверхностно модифицированных многоострийных кремниевых катодных матриц.

DOI: 10.21883/JTF.2019.06.47646.274-18

\section{Введение}

В вакуумно-плазменной микроэлектронике одним из наиболее привлекательных материалов для полевых источников электронов при создании активной элементной базы остается кристаллический кремний. В первую очередь это обусловлено развитой технологической базой, а также известными люминесцентными свойствами нанокристаллического кремния, которые позволяют надеяться на создание в будущем сверхбыстродействующих радиационно стойких кремниевых интегральных схем с оптической связью. Основными недостатками, которые препятствуют широкому использованию кремния в этом направлении, являются высокие напряжения электрических полей, необходимые для возбуждения автоэмиссии. В настоящее время их уменьшение достигается в основном в результате совершенствования электровакуумных технологий твердотельной микро- и наноэлектроники и перехода к устройствам со сверхмалыми размерами. Наиболее значительные успехи получены при создании на кремнии острийных решеток автоэмиссионных катодов с радиусом кривизны атомарных размеров (менее $1 \mathrm{~nm}$ ) [1], что позволяет существенно понизить рабочие напряжения. Однако использование высокоаспектных эмиттеров, а также различных конструктивных решений, направленных на повышение фактора усиления поля $K$ путем уменьшения радиусов эмитирующих острий, диаметров отверстий в управляющих электродах или создания нанолезвийных планарных структур, приводит к усложнению технологии изготовления и сопровождается, как правило, снижением надежности и увеличением себестоимости автоэмиссионных устройств [2]. В связи с этим большой как фундаментальный, так и прикладной интерес представляют исследования альтернативных путей, направленных на повышение воспроизводимости и улучшение эмиссионных характеристик автокатодов, которые были бы связаны не только с конструктивными, но и с физико-химическими модификациями эмитирующих поверхностей кремниевых кристаллов.

В работе [3] показано, что плазмохимическая обработка поверхностей полупроводников с использованием различных химически активных газовых сред вызывает устойчивую модификацию их электронных свойств. Модификация поверхностей проявляется прежде всего в ослаблении явлений, связанных с использованием эффектов поля, люминесценции, фото- и поверхностной проводимости, в изменении работы выхода и др. [4]. Однако, с другой стороны, она позволяет в определенной степени активно формировать электронные свойства поверхности обрабатываемых полупроводниковых кристаллов и придавать им необходимые функциональные свойства.

Цель настоящей работы - исследования возможности плазмохимической модификации электронных свойств поверхностей для снижения рабочих напряжений полевых источников электронов, изготовленных на основе поверхностно наноструктурированных кристаллов кремния различных типов электропроводности.

\section{Методика и результаты исследований}

Структурирование поверхностей кристаллов кремния различных типов проводимости с удельным сопротивлением $0.01-0.02 \Omega \cdot \mathrm{cm}$ осуществлялось в одном технологическом цикле осаждением островковых углеродных масковых покрытий в микроволновой плазме паров этанола после удаления естественного оксидного покрытия в низкоэнергетичной плазме хладона-14 и последующего высокоанизотропного плазмохимического травления по 

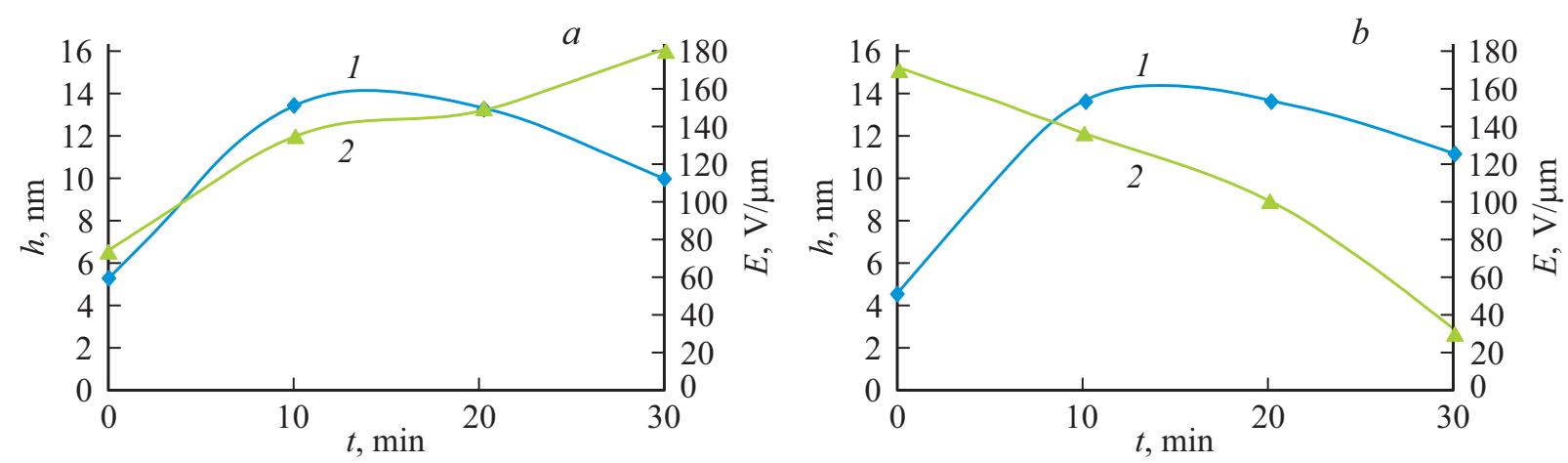

Рис. 1. Зависимости высот выступов (1) и напряженностей электрического поля полевой эмиссии электронов при плотности автоэмиссионного тока $50 \mu \mathrm{A} / \mathrm{cm}^{2}(2)$ от длительности масочного травления пластин кремния $(100) n$ - $(a)$ и $p$ - $(b)$ типов с предварительным травлением в плазме хладона-14.
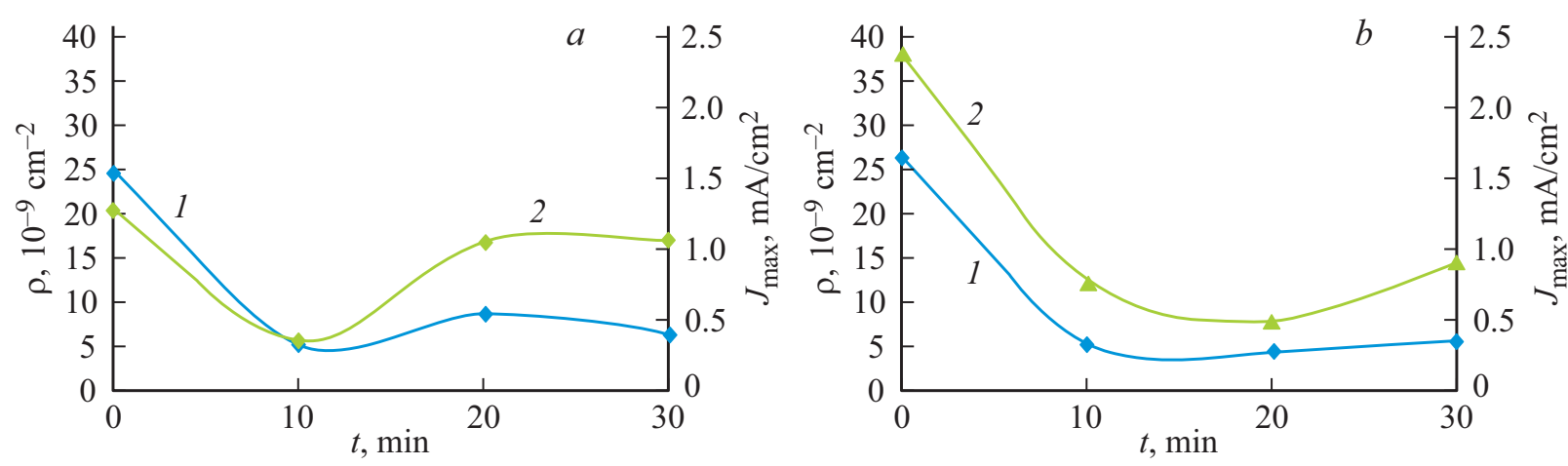

Рис. 2. Зависимости поверхностных плотностей выступов (1) и плотностей максимальных токов автоэмиссии (2) от длительности масочного травления кремния (100) $n$ - $(a)$ и $p$ - $(b)$ типов с предварительным травлением в плазме хладона-14.

методике, изложенной в [5]. Наноморфология поверхностей изучалась с помощью сканирующего атомносилового микроскопа P4-SPM-MDT. В качестве зонда использовались стандартные кремниевые кантилеверы CSG10 пирамидальной формы с радиусом закругления $10 \mathrm{~nm}$ и жесткостью $0.1 \mathrm{~N} / \mathrm{m}$. Поле сканирования составляло $3 \times 3 \mu \mathrm{m}$. Обработка результатов измерений производилась с использованием программного обеспечения микроскопа. Исследования автоэмиссионных свойств кремниевых пластин осуществлялись в условиях высокого вакуума $\left(10^{-5} \mathrm{~Pa}\right)$ на диодной структуре, способной изменять расстояние между электродами с точностью до $1 \mu \mathrm{m}$.

На рис. 1,2 приведены экспериментальные зависимости параметров наноморфологий, напряженностей электрических полей полевой эмиссии электронов, обеспечивающих плотности автоэмиссионного тока $50 \mu \mathrm{A} / \mathrm{cm}^{2}$, a также максимальных плотностей автоэмиссионных токов от длительностей высокоанизатропного масочного травления пластин кремния различных типов проводимости (значениям координат при $t=0 \mathrm{~s}$ соответствуют морфологические и автоэмиссионные характеристики кремниевых пластин до проведения высокоанизотропного масочного травления). Видно, что характер зависимостей морфологических параметров структурированных поверхностей кремния обоих типов проводимостей от длительностей маскового травления практически одинаков. В обоих случаях с увеличением длительностей плазмохимического травления высоты выступов имеют максимумы величиной $14 \mathrm{~nm}$ при длительности около $10 \mathrm{~min}$. При дальнейшем увеличении длительностей травления высоты выступов медленно уменьшаются. Поверхностные плотности выступов после $10 \mathrm{~min}$ высокоанизотропного масочного травления выходят на насыщение и в дальнейшем имеют практически одинаковые значения, которые составляют $(5-7) \cdot 10^{9} \mathrm{~cm}^{-2}$.

В отличие от морфологических характер изменений автоэмиссионных свойств полученных многоострийных катодных матриц от длительностей масочного травления существенно зависит от типа электропроводности полупроводника. Для пластин кремния $n$-типа независимо от характера изменения высот выступов в интервале длительностей травления от нуля до $30 \mathrm{~min}$ наблюдается более чем двукратное монотонное увеличение напряженностей полей, при которых плотность автоэмиссионного тока сохраняется неизменной и равной $50 \mu \mathrm{A} / \mathrm{cm}^{2}$ (рис. 1,a). Максимальные плотности автоэмиссионных токов как в отсутствие травления, так и при длительностях травления в интервале от 20 до $30 \mathrm{~min}$ остаются практически неизменными и равными 


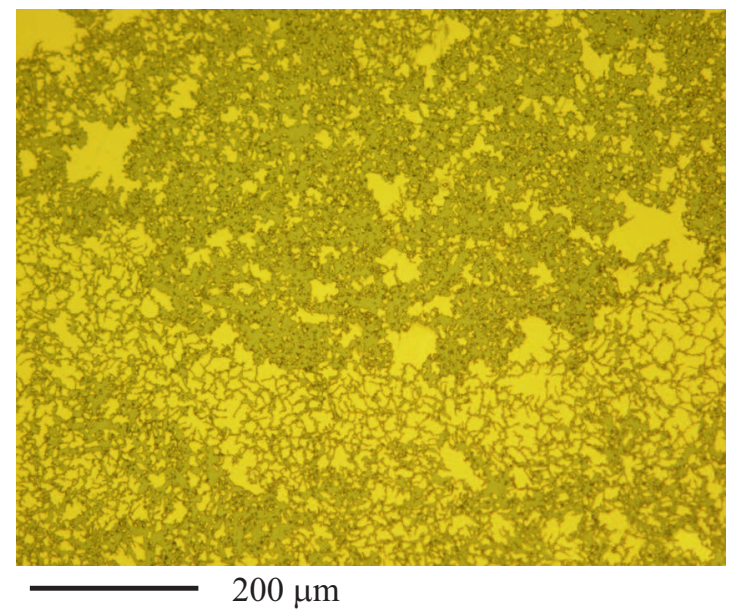

Рис. 3. Изображение с оптического микроскопа области разрушения кремниевой многоострийной катодной матрицы.

около $1 \mathrm{~mA} / \mathrm{cm}^{2}$. Исключением является длительность масочного травления $10 \mathrm{~min}$. При этой длительности травления, несмотря на наибольшую высоту выступов, максимальная плотность автоэмиссионного тока имеет минимальную величину, равную $0.5 \mathrm{~mA} / \mathrm{cm}^{2}$. При увеличении анодного напряжения с целью превышения полученных максимальных плотностей автоэмиссионных токов происходит необратимое разрушение катодных матриц. Области разрушения катодных матриц на кристаллах кремния обоих типов проводимости имеют вид, который характерен для электрических пробоев диэлектрических материалов (рис. 3).

Для пластин кремния $p$-типа при фиксированной плотности автоэмиссионного тока $50 \mu \mathrm{A} / \mathrm{cm}^{2}$, также независимо от характера изменения высот выступов, наблюдается практически пятикратное монотонное уменьшение напряженностей полей автоэмиссии при изменении длительностей маскового травления в том же интервале (рис. 1,b). Характер изменения максимальных плотностей автоэмиссионных токов, также как для кремния $n$-типа коррелирует с изменением поверхностных плотностей автоэмиссионных выступов. В отсутствие масочного травления (при $t=0)$ максимальная плотность автоэмиссионного тока и напряженность внешнего электрического поля, обеспечивающая фиксированную плотность автоэмиссионного тока $50 \mu \mathrm{A} / \mathrm{cm}^{2}$, у кристаллов кремния $p$-типа в 2 раза больше, чем у пластин кремния $n$-типа.

\section{Обсуждение результатов}

В настоящее время единственным аналитическим выражением, описывающим туннельную эмиссию электронов при приложении сильных электрических полей, является формула Фаулера и Нордгейма, которая хорошо описывает полевую эмиссию из металлов в вакуум [6,7]:

$$
J=A \frac{E_{i}^{2}}{\varphi} \cdot \exp \left(B \varphi^{3 / 2} / E_{i}\right)
$$

где $A, B$ - некоторые коэффициенты, $\varphi-$ потенциал работы выхода электрона из материала катода, $E_{i}$ - электрическое поле на отдельном (усредненном) микровыступе катодной структуры. Электрическое поле на микровыступе связано со средней величиной напряженности внешнего электрического поля $E_{0}$ через коэффициент усиления поля $K$, который определяется морфологией поверхности

$$
E_{i}=K E_{0} .
$$

Таким образом, окончательный вид аналитического выражения зависимости $j(E)(1)$ примет вид

$$
J=A \frac{\left(E_{0} K\right)^{2}}{\varphi} \exp \left(-B \varphi^{3 / 2} /\left(E_{0}-K\right)\right)
$$

Рост плотности тока с повышением напряженности внешнего электрического поля $E_{0}$ заканчивается в металлах при $j=10^{8}-10^{10} \mathrm{~A} / \mathrm{cm}^{2}$ вакуумным пробоем и гибелью эмиттера. Этому предшествует более интенсивная, но кратковременная взрывная электронная эмиссия.

Согласно выражению (3), уменьшение (увеличение) напряженности внешнего электрического поля на отдельных выступах $E_{i}$, при котором плотность автоэмиссионного тока остается фиксированной, возможно только при увеличении (уменьшении) коэффициента усиления поля $K$ таким образом, чтобы произведение $K \cdot E_{0}$ оставалось постоянным. Однако из зависимостей, приведенных на рис. 1, 2, видно, что для пластин $n$-типа в интервале длительностей травления до $10 \mathrm{~min}$ и пластин р-типа при длительностях травления больше $10 \mathrm{~min}$ такие соотношения не соблюдаются - высоты выступов и, следовательно, коэффициенты усиления поля на них, а также напряженности внешних электрических полей, при которых автоэмиссионный ток остается фиксированной величиной, изменяются не обратно пропорционально. Это свидетельствует о том, что взаимосвязь установленных закономерностей изменения морфологических и автоэмиссионных характеристик поверхностно структурированных с использованием фторсодержащей плазмы кремниевых пластин не может быть интерпретирована в рамках представлений Фаулера-Нордгейма. Характеры изменения напряженностей внешних электрических полей, обеспечивающих фиксированную плотность автоэмиссионного тока $50 \mu \mathrm{A} / \mathrm{cm}^{2}$, а также максимальных плотностей автоэмиссионных токов, при превышении которых происходят разрушения катодных матриц, свидетельствуют о том, что их величины, вероятнее всего, не являются основной причиной разрушения полевых многоострийных катодных матриц, изготовленных на кристаллах кремния. Так, для катодных матриц на кристаллах кремния $p$-типа необратимые разрушения происходят как при низких напряженностях электрических 
полей и небольших значениях плотностей максимальных автоэмиссионных токов, которые имеют место при длительностях масочного травления $30 \mathrm{~min}$, так и при более чем пятикратном увеличении напряженностей электрических полей при одновременном практически трехкратном увеличении максимальных плотностей токов, которые наблюдаются в отсутствие масочного травления при $t=0$ (рис. 2, $b$ ).

При ионно-плазменном травлении естественного оксидного покрытия кремния в среде $\mathrm{CF}_{4}$, которое проводилось перед осаждением углеродного масочного покрытия, химически активными частицами являются ионы $\mathrm{C}^{+}, \mathrm{CF}_{n}^{+}$, где $n=1 \ldots 4$, а также радикалы $\mathrm{CF}_{n}$ и нейтральные атомы фтора. При хемосорбции они образуют на кремнии монослойные адкомплексы $\mathrm{Si}-\mathrm{C}$, $\mathrm{Si}-\mathrm{F}$ и $\mathrm{Si}-\mathrm{C}-\mathrm{F}[8]$, которые имеют сильные энергии химической связи $(4.55,5.6$ и $5.64 \mathrm{eV}$ соответственно) и превышают энергию химической связи между атомами в кремнии. После удаления естественного оксидного покрытия эти соединения пассивируют атомно-чистую поверхность кремния. Благодаря более высокой по отношению к кремнию и углероду электроотрицательности атомарного фтора на поверхности кремния индуцируется отрицательный заряд. Непосредственно на границе

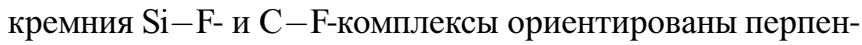
дикулярно поверхности раздела, придавая поверхности некоторый суммарный дипольный момент. Для перемещения электрона через образовавшийся дипольный слой необходимо совершить дополнительную работу. Это приводит к увеличению работы выхода по сравнению с атомно-чистой поверхностью кремния. Кроме того, отрицательный заряд на поверхности кремния $n$-типа приводит к обеднению приповерхностного слоя полупроводника основными носителями, а на поверхности кремния $p$-типа - к обогащению. В первом случае это сопровождается увеличением толщины двойного электрического слоя, экранирующего отрицательный заряд на поверхности, и уменьшением электропроводности приповерхностного слоя. Во-втором, напротив, приповерхностный слой обогащается основными носителями и его электропроводность увеличивается. В соответствии с этими изменениями электропроводности изменяются напряженности анодного поля, при которых плотность автоэмиссионного тока сохраняет фиксированное значение. По этой причине в отсутствие масочного травления плотности автоэмиссионных токов для катодных матриц на подложках кремния $n$-типа существенно меньше, чем для катодных матриц на кремнии $p$-типа (рис. 2, кривые 2 при $t=0$ ).

При осаждении островкового углеродного маскового покрытия из плазмы паров этанола, которое осуществляется при отрицательном смещении на подложкодержателе, благодаря низкой энергии $\mathrm{C}-\mathrm{C}$ химической связи $(2.74 \mathrm{eV})$, наиболее вероятным является формирование $\mathrm{Si}-\mathrm{C}-\mathrm{C} \ldots \mathrm{C}$ и $\mathrm{C}-\mathrm{C}-\mathrm{C} \ldots \mathrm{C}$ цепочечных комплексов. Осаждение углеродного покрытия на кристаллы кремния $n$-типа, когда реализуется прямое вклю- чение полупроводника, протекает в более равновесных условиях по сравнению с осаждением на кристаллы кремния $p$-типа. Это обусловлено тем, что процессы, связанные с обменом электронами между бомбардирующими углеродосодержащими ионами и поверхностью кремния, происходят в первом случае более интенсивно. При бомбардировке ионами углерода поверхности кремния $p$-типа с обратным включением полупроводника на подложкодержателе к источнику питания процесс потенциальной эмиссии электронов протекает в условиях нехватки электронов. Это способствует образованию в объеме осажденного углеродного масочного покрытия преимущественно акцепторных электронных состояний.

В процессе осаждения атомы углерода ,замуровывают ${ }^{6}$ оставшиеся после плазмохимического травления

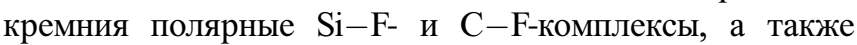
различные локализованные электронные состояния. При больших толщинах углеродного маскового покрытия разориентация диполей увеличивается, а суммарный дипольный момент эмитирующих выступов катодной матрицы уменьшается [4]. Благодаря этому катодные матрицы на кремнии $n$-типа в отсутствие масочного травления имеют наименьшую работу выхода электронов и минимальную напряженность электрического поля, при которой плотность автоэмиссионного тока составляет заданную величину в $50 \mu \mathrm{A} / \mathrm{cm}^{2}$ (рис. $1, a$ ).

При автоэлектронной эмиссии из катодных матриц на кремнии $p$-типа электроны, которые под действием внешнего электрического поля анода, инжектируются в эмитирующие выступы, захватываются ловушками захвата углеродной маски. Возникшие отрицательный пространственный и поверхностный заряды масочного покрытия увеличивают работу выхода электронов. В результате этого напряженность поля, обеспечивающая заданную плотность автоэмиссионного тока в отсутствие масочного травления на кремниевых подложках $p$-типа является максимальной (рис. $1, b$, кривая 2 для $t=0$ ).

При уменьшении толщины углеродного масочного покрытия, которое происходит при высокоанизатропном масочном травлении за счет конечной селективности травления кремния и углерода, независимо от изменения высоты эмиттирующих выступов на кремнии $n$-типа (рис. 1, $a$, кривая 1) из-за более упорядоченного расположения нормально ориентированных к поверхности $\mathrm{Si}-\mathrm{F}$ и C-F-диполей увеличиваются дипольный момент эмиттирующей поверхности и работа выхода электронов. Это вызывает монтонный рост напряженности электрического поля, при котором плотность автоэмиссионного тока сохраняет заданное значение (рис. 1, а, кривая 2).

При увеличении длительности высокоанизотропного травления в катодных матрицах на кремнии $p$-типа за счет уменьшения толщины углеродного масочного покрытия происходит уменьшение поперечного сопротивления катодной структуры и величины приповерхностного заряда электронов, встроенных в ловушки захвата. Это приводит к уменьшению работы выхода электронов и монотонному уменьшению напряженности поля, 
обеспечивающего заданную плотность автоэлектронного тока (рис. $1, b$, кривая 2).

Эффективная полевая эмиссия в кремниевых катодных матрицах с фторуглеродным покрытием, вероятнее всего, осуществляется за счет двухступенчатого туннелирования электронов из кремниевой подложки во фторуглеродное покрытие и затем в вакуум [9]. В соответствии с этим такие катодные матрицы можно представить состоящими из нескольких последовательно соединенных конденсаторов. В первом конденсаторе диэлектриком является вакуумный промежуток. Его емкость определяется расстоянием между катодом и анодом и в условиях экспериментов является фиксированной величиной. Емкость другого конденсатора определяется шириной двойного электрического слоя в приповерхностных областях кремниевых острий, образованного диполями хемосорбированных на кремнии электротрицательных атомов фтора. Как известно, при последовательном соединении все конденсаторы заряжаются одинаковым количеством электричества. Однако напряжения на конденсаторах будут различными, так как для заряда одним и тем же количеством электричества конденсаторов различной емкости требуются различные напряжения. Чем меньше емкость конденсатора, тем большее напряжение необходимо для того, чтобы зарядить этот конденсатор требуемым количеством электричества, и наоборот. При больших напряженностях внешних электрических полей, предназначенных для получения максимальных плотностей автоэмиссионных токов, напряжение, в первую очередь на конденсатоpe c меньшей емкостью, может достигать пробивного значения. Результатом этого является возникновение электрического пробоя и разрушение автоэмиссионной структуры (рис. 3).

При приложении анодного напряжения к катодной матрице с фторсодержащим карбид кремниевым покрытием за счет проникновения поля увеличивается дипольный потенциал на границе кремния. Для катодных матриц на кремнии $n$-типа это приводит к увеличению области пространственного заряда, уменьшению поперечной электропроводности и емкости второго конденсатора. При достижении анодного напряжения порога генерации автоэмиссии падение напряжения при прохождении электронов через масочное покрытие уменьшает отрицательный потенциал в контакте кремний-дипольное фторсодержащее кремниевое покрытие. Это несколько увеличивает поперечную электропроводность двойного электрического слоя в приповерхностных областях кремниевых острий и уменьшает поверхностную плотность индуцированного заряда на обкладках обоих, последовательно соединенных конденсаторов. При высоких напряженностях электрических полей анодного электрода, используемых для получения больших плотностей автоэмиссионных токов, из-за отсутствия электропроводности в двойном электрическом слое, заряд на обкладках конденсаторов увеличивается. При превышении электрического поля пробивного значения для диэлектрика второй конденсаторной структуры происходит электрический пробой и разрушение катода. Для многоострийной катодной кремниевой матрицы $n$-типа ограничение в проводимости и, как следствие, величины максимальной плотности автоэмиссионного тока, наступает при длительности масочного травления около $20 \mathrm{~min}$. При больших длительностях травления максимальные плотности автоэмиссионных токов перестают изменяться (рис. 2, $a$, кривая 2). С этой величины длительности масочного травления увеличение анодного напряжения приводит к накоплению заряда и электрическому пробою в катодной матрице.

При небольших напряженностях электрического поля анода при полевой эмиссии электронов из катодной матрицы на кремнии дырочного типа проводимости в его контакте с фторсодержащим карбид кремниевым покрытием реализуется прямое включение полупроводника. В этом случае поперечная проводимость структуры и плотность автоэмиссионных токов с увеличением электрического поля анода увеличиваются. Благодаря этому максимальные плотности автоэмиссионных токов в катодных матрицах на кремнии р-типа в отсутствие масочного травления существенно выше, чем в катодных матрицах на кремнии донорного типа проводимости (рис. 2, кривые 2 при $t=0 \mathrm{~min}$ ). Ограничением максимальной плотности автоэмиссионного тока является превышение анодного напряжения внутреннего поля диполей на границе с полупроводником. С этого момента увеличение анодного напряжения приводит к возникновению двойного электрического слоя и обеднению приповерхностной области кремния основными носителями. Связанные с этим уменьшения проводимости и емкости конденсаторной структуры с диэлектриком в виде двойного электрического слоя на границе кремния приводят к увеличению внутреннего электрического поля. Его превышение электрической прочности слоя, обедненного основными носителями полупроводника, приводит к электротепловому пробою и разрушению катодной структуры.

С увеличением длительности масочного травления за счет уменьшения толщины слоя масочного покрытия со встроенным зарядом, увеличения электропроводности оставшейся его части и уменышения падения напряжения ускоряется переход к режиму обеднения приповерхностной области основными носителями. Это приводит к уменьшению электропроводностей эмитирующих выступов и накоплению электрического заряда по разные стороны двойного электрического слоя с последующим разрушением катодной матрицы. Результатом этих процессов является уменьшение максимальных плотностей автоэмиссионного тока с увеличением длительностей масочного травления. Уменьшение максимальных плотностей автоэмиссионного тока происходит несмотря на уменьшение работы выхода электронов, связанное с уменьшением отрицательного заряда встроенных в поверхностных ловушках захвата электронов, и напряженностей полей автоэмиссии при 
получении фиксированной плотности автоэмиссионного тока, равной $50 \mu \mathrm{A} / \mathrm{cm}^{2}$ (рис. $1, b$, кривая 2).

\section{Заключение}

1. При плазмохимической модификации поверхностей полупроводников с использованием электроотрицательных химических элементов определяющее влияние на величину электрического поля, обеспечивающего заданную полевую эмиссию электронов, оказывает не коэффициент усиления электростатического поля на эмитирующих выступах, а ближнеполевой суммарный дипольный момент поверхности.

2. Взаимосвязь между напряженностями электрических полей, обеспечивающих фиксированную плотность автоэмиссионного тока, и морфологическими характеристиками эмитирующей поверхности катодных матриц на основе кристаллов кремния различных типов проводимости, за исключением некоторых случаев, не может быть описана законом Фаулера-Нордгейма.

3. При полевой эмиссии электронов из наноструктурированных катодных матриц с фторуглеродным масочным покрытием фиксированные плотности автоэмиссионных токов могут быть получены в зависимости от типа электропроводности полупроводника и модификации поверхности как при увеличении напряженности поля анода, так и при его уменьшении.

4. Превалирующую роль в установлении токов полевой эмиссии многоострийных полупроводниковых катодных матриц с хемосорбированными атомами с заданным электронным сродством к электрону играют проникновение поля анода и его влияние на дипольные моменты поверхности. Изменение дипольного момента позволяет управлять напряжениями полевой эмиссии электронов и получать фиксированные плотности автоэмиссионных токов при различных рабочих напряжениях.

5. Причинами разрушения полупроводниковых полевых катодных матриц при приложении к ним сильных внешних электрических полей являются накопление зарядов и электротепловой пробой двойного электрического слоя, экранирующего объем полупроводника от действия электрических полей.

Исследование выполнено за счет гранта Российского научного фонда (проект № 16-19-10033).

\section{Список литературы}

[1] Marcus R.B., Ravi T.S., Gmitter T. et al. // Appl. Phys. Lett. 1990. Vol. 56. N 3. P. 236-238.

[2] Гуляев Ю.В., Абаньшин Н.П., Горфинкель Б.И., Морев С.П., Резчиков А.Ф., Синицын Н.И., Якунин А.Н. // Письма в ЖТФ. 2013. Т. 39. Вып. 11. С. 63-70.

[3] Яфаров Р.К. // ФТП. 2014. Т. 48. Вып. 4. С. 529-534. DOI: $10.1134 / \mathrm{S} 1063782614040277$

[4] Оура К., Лифиии В.Г., Саранин А.А. и др. Введение в физику поверхности. М.: Наука, 2006. С. 490.
[5] Яфаров Р.К., Шаныгин В.Я. // ФТП. 2017. Т. 51. Вып. 4. C. 558-562. DOI: 10.21883/JTF.2019.06.47646.274-18

[6] Fowler R.H., Nordheim L.W. // Proc. R. Soc. London. A. 1928. Vol. 119. P. 173.

[7] Усанов Д.А., Яфаров Р.К. Методы получения и исследования самоорганизующихся наноструктур на основе кремния и углерода. Саратов: Сар. ГУ, 2011. 126 с.

[8] Яфаров Р.К. Физика СВЧ вакуумно-плазменных нанотехнологий. М.: Физматлит, 2009. 216 с.

[9] Давидович М.В., Яфаров Р.К. // ЖТФ. 2018. Т. 88. Вып. 2. C. 283-293. DOI: $10.1134 / \mathrm{S} 106378421802010 \mathrm{X}$ 